\title{
East Asian \\ Science, Technology, and Medicine
}

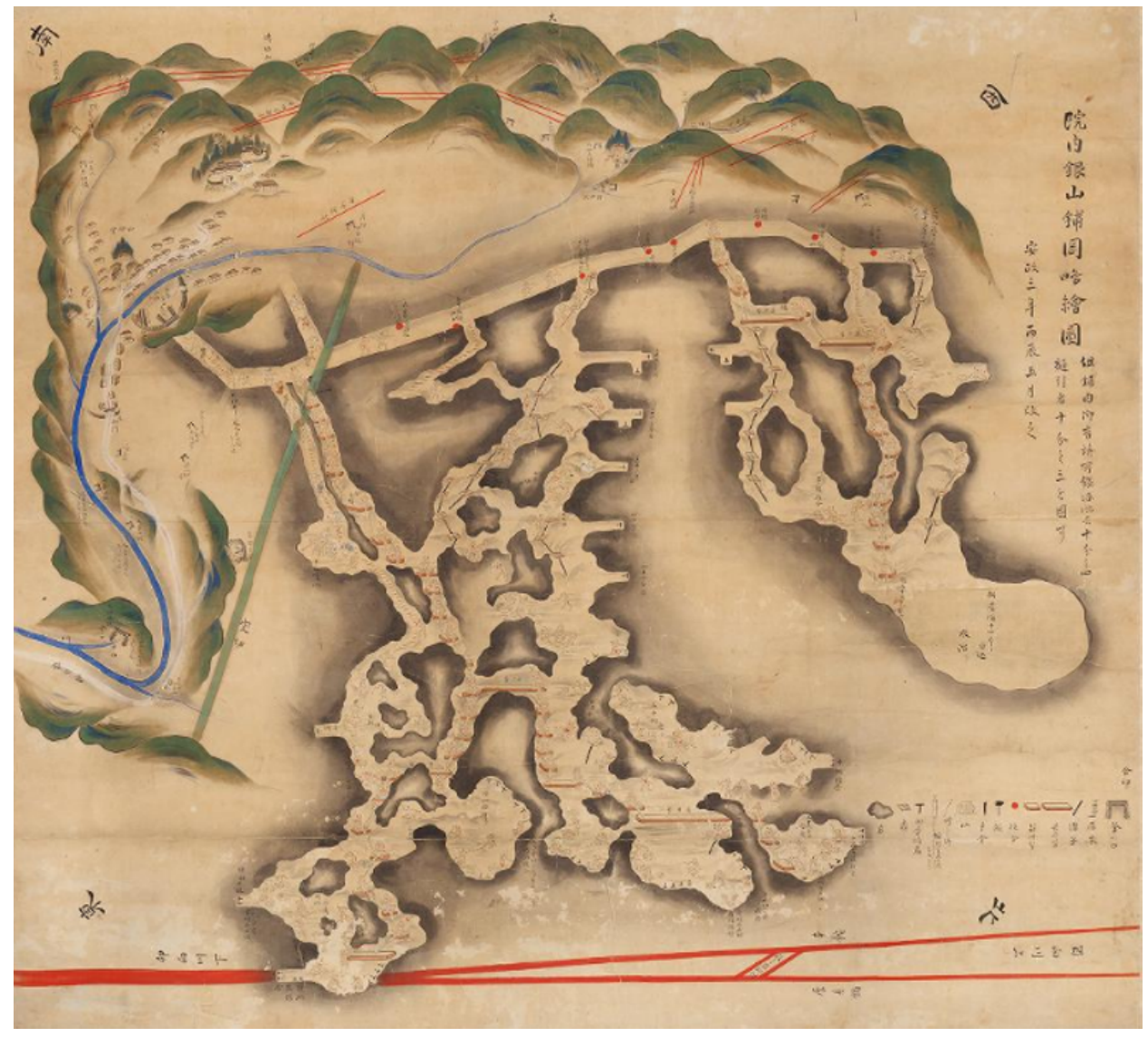

Number $5 \mathrm{I}-52 \bullet 2020$

International Society for the History of East Asian Science, Technology, and Medicine

Chine, Corée, lapon-UMR 8I73

CNRS \& EHESS, Paris 
Cover illustration:

Map of mine shafts and tunnels in the Innai silver mine Title: Innai ginzan shikioka ryakuezu 院内銀山鋪岡略絵龱 Creator: Ōnuki Tadanori 大貫忠誨 Year: 1856

Source: Mining Museum of Akita University 秋田大学国際資源学部附属鉱業博物館 

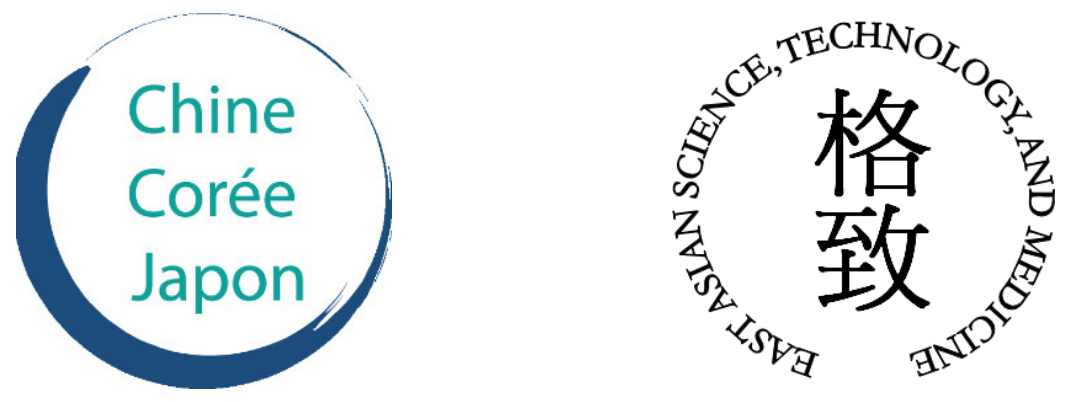

International Society for the History of East Asian Science, Technology, and Medicine 